\title{
Alterações físico-químicas e microbiológicas durante o armazenamento de doces de umbu (Spondias tuberosa Arr. Câmara) verde e maduro
}

\author{
Physico-chemical and microbiological changes during storage of green and ripe umbu marmalade
}

\author{
Maria Lúcia Almeida MARTINS' ${ }^{1}$, Soraia Vilela BORGES ${ }^{2 *}$, Admilson Costa CUNHA ${ }^{3}$, \\ Filde Pereira OLIVEIRA ${ }^{3}$, Ivanilda Maria AUGUSTA ${ }^{3}$, Elizete AMORIM ${ }^{3}$
}

\begin{abstract}
Resumo
O umbuzeiro (Spondias tuberosa Arr. Câmara) é uma planta de grande valor econômico para a região semiárida nordestina, notadamente pela produção de doces em massa. Este trabalho teve como objetivo monitorar a vida de prateleira de quatro formulações de doces em massa de umbu verde e maduro à temperatura de $30^{\circ} \mathrm{C}$ durante 120 dias. As alterações físico-químicas e microbiológicas foram avaliadas no referido tempo. Os resultados mostraram um decréscimo na atividade de água, um aumento nos sólidos solúveis e no açúcar redutor; pH e acidez mantiveram estáveis; e uma tendência à redução no conteúdo de açúcar não redutor em ambos os doces. Os produtos foram microbiologicamente estáveis. Recomenda-se o uso de pectina ao processo de formulações de umbu maduro e goma xantana ou xarope de glicose para produção de doces de umbu verde.

Palavras-chave: frutas; processamento de frutas; vida prateleira.
\end{abstract}

\begin{abstract}
The umbu (Spondias tuberosa Arr. Câmara) tree is of high economic value to the semi-arid Northeast area of Brazil due to umbu jam production. This work aimed to monitor the shelf life of four marmalade formulations made from green and ripe umbu, which were kept at $30{ }^{\circ} \mathrm{C}$ for 120 days. The physical, chemical, and microbiological alterations were evaluated during the time specified. The results showed a decrease in water activity; an increase in the soluble solids, and a reduction in sugar; $\mathrm{pH}$ and acidity remained stable; and there was a tendency to lower sucrose content in both jams. The products were microbiologically stable. The use of pectin is recommended to process the formulations made from ripe umbu, and either xanthan gum or glucose syrup to produce jam from the green umbu.

Keywords: fruit; fruit processing; shelf life.
\end{abstract}

\section{Introdução}

O doce de umbu (Spondias tuberosa Arr. Cam.) de polpas nos estádios de maturação verde e madura representa uma ótima alternativa para os moradores da região semiárida nordestina, pois reduz as perdas pós-colheita e constitui fonte de renda adicional. Entretanto, estes produtos exibem elevada sinérese e escurecimento durante o armazenamento, devido à alta acidez, baixo $\mathrm{pH}$ e utilização de embalagens inadequadas (PINTO et al., 2001; POLICARPO et al., 2002).

A sinérese e o escurecimento de doces muito ácidos, como o obtido de umbu de polpa verde, podem ser evitados pelo ajuste do $\mathrm{pH}$ e o uso de pectina (POLICARPO et al., 2007). Estes fenômenos também podem ser controlados ou evitados com o uso de gomas e amido modificado, os quais são estáveis a baixos pH e altas temperaturas de cocção (MAO; TANG; SWANSON, 2001; RENARD; Van de VELDE; VISSCHERS, 2001). Amido modificado e goma xantana foram testados por Martins et al. (2007), apresentando um bom índice de aceitação para doces obtidos de polpas de umbu nos estádios de maturação verde e maduro (65-80\%).

A vida útil de um alimento representa o período em que se encontra em boas condições sensoriais e microbiológicas para ser consumido sem prejudicar o paladar e a saúde, condições estas dependentes de transformações físicas, químicas e microbiológicas durante o armazenamento, que, por sua vez, dependem da natureza do produto (tipo e quantidade de ingredientes), da embalagem e das condições de armazenamento (temperatura, umidade relativa, tempo de armazenamento) (WICKLUND et al., 2005; KHOUYIEH; ARAMOUNI; HERALD, 2005; VASQUES et al., 2006; MOURA et al., 2007; POLICARPO et al., 2007).

Este trabalho teve como objetivo verificar as alterações físico-químicas e microbiológicas em quatro formulações de doce em massa de umbu de polpa verde e madura, estocados sob condições controladas $\left(30^{\circ} \mathrm{C} / 75 \%\right.$ UR) durante 120 dias.

Recebido para publicação em 21/1/2008

Aceito para publicação em 13/11/2008 (003166)

${ }^{1}$ Departamento de Economia Doméstica, Universidade Federal Rural do Rio de Janeiro - UFRRJ, E-mail: luciaalmei@yahoo.com.br

2 Departamento de Ciência dos Alimentos, Universidade Federal de Lavras - UFLA, E-mail: sborges@ufla.br

${ }_{3}^{3}$ Departamento de Tecnologia dos Alimentos, Universidade Federal do Rio de Janeiro - UFRRJ, E-mails: admilsoncunha@bol.com.br; eng_filde@yahoo.com.br; amorizete@ufrrj.br;ivanildamaria@yahoo.com.br

${ }^{*}$ A quem a correspondência deve ser enviada 


\section{Material e métodos}

\subsection{Matéria-prima}

Frutos de umbu nos estádios de maturação verde e maduro foram obtidos da EMBRAPA/CPATSA, localizada em Petrolina - Pernambuco. Na planta piloto da UFRRJ, eles foram selecionados, branqueados para inativação da peroxidase $\left(100{ }^{\circ} \mathrm{C} / 3\right.$ minutos), despolpados e resfriados.

\subsection{Formulações}

Foram processadas oito formulações de doce em massa, quatro de doce de umbu verde e quatro de doce de umbu maduro, de acordo com procedimentos descritos por Martins et al. (2007). A relação 1:1 de polpa/açúcar foi mantida para ambos os doces. Os demais ingredientes para o doce de umbu verde variaram nas seguintes proporções: F1 (0,3\% de goma xantana); F2 (0,3\% de goma xantana e 5\% de xarope de glicose); F3 (0,5\% de amido modificado) e F4 (0,5\% de amido modificado e $5 \%$ de xarope de glicose). Para o doce de umbu maduro a formulação F1 (sem aditivos) e nas demais foram adicionados os aditivos: F2 (0,5\% de pectina); F3 (0,3\% de goma xantana); e F4 (0,5\% de amido modificado e 5\% de xarope de glicose), para obter melhor brilho e retardar a cristalização, conforme recomendado por Jackix (1988). O pH das polpas foi corrigido com $\mathrm{CaCO}_{3}$ (de 2,65 para 3,4) para evitar sinérese nos doces durante o armazenamento.

\subsection{Análises físico-químicas}

Foram realizadas análises em triplicata de acidez total titulável (g de ácido cítrico.100 $\mathrm{g}^{-1}$ ); açúcares redutores em glicose e não redutores em sacarose $\left(\mathrm{g} .100 \mathrm{~g}^{-1}\right)$; sólidos solúveis totais ( ${ }^{\circ}$ Brix) em refratômetro portátil (DP INSTRUMENTS, São Paulo) de acordo com os métodos recomendados pela AOAC (1992); pH em pH metro TECNAL (Piracicaba, SP) segundo IAL (1985); e a atividade de água (Aw) foi medida em aparelho AQUALAB (modelo CX-2, Decagon Devise, Pullman, WA).

\subsection{Análises microbiológicas}

Para a contagem de bolores e leveduras utilizou-se a metodologia descrita por Speack (1976).

\subsection{Análise estatítica}

O planejamento experimental foi repetido 3 vezes e os resultados foram analisados através da análise de variância, aplicando-se modelos lineares para expressar os resultados significativos com o tempo de armazenamento, ao nível de 5\% de probabilidade (FONSECA; MARTINS; TOLEDO, 1995).

\section{Resultados e discussão}

\subsection{Análises físico-químicas}

Não houve diferença significativa no $\mathrm{pH}(\mathrm{p}<0,05)$ entre quaisquer formulações para os doces de umbu verde e maduro ao longo do tempo do armazenamento, como mostra a Tabela 1.
Observa-se no doce de umbu verde uma tendência à elevação nas formulações F2, F3 e F4 após 60 dias de armazenamento, enquanto que para o doce de umbu maduro o $\mathrm{pH}$ manteve-se estável em todas as formulações durante o armazenamento.

Policarpo et al. (2007), em estudo de conservação de doces em massa da polpa de umbu verde, armazenados em embalagens de polipropileno à temperatura ambiente $\left(33^{\circ} \mathrm{C}\right)$, obtiveram o pH estável durante 90 dias. Xavier (1999) também obteve o $\mathrm{pH}$ constante para doces em massa de polpas mistas de umbu e geleia de umbu madura, durante o armazenamento de 63 e 120 dias, respectivamente. Resultados semelhantes foram encontrados por Khouryeh, Aramouni e Herald (2005) para geleias de uva. Já Nachtigall et al. (2004) encontraram um decréscimo de $\mathrm{pH}$ durante o armazenamento de geleia de amora-preta de baixa caloria.

Verificou-se também que não houve diferença $(\mathrm{p}<0,05)$ para a acidez total titulável em ambos os doces ao longo do tempo de armazenamento (Tabela 2). Entretanto, nota-se uma tendência a um ligeiro aumento de acidez titulável até 60 dias em todas as formulações, de ambos os doces, com exceção da

Tabela 1. Efeito do armazenamento sobre o $\mathrm{pH}$ de doces de umbu verde e maduro.

\begin{tabular}{ccccc}
\hline \multirow{2}{*}{ Doce } & Formulação & \multicolumn{3}{c}{ Tempo de armazenamento (dias) } \\
\cline { 2 - 5 } & & 0 & 60 & 120 \\
\hline Verde $^{* *}$ & F1 & $3,54^{\text {a* }}$ & $3,51^{\mathrm{a}}$ & $3,57^{\mathrm{a}}$ \\
& $\mathrm{F} 2$ & $3,55^{\mathrm{a}}$ & $3,48^{\mathrm{a}}$ & $3,74^{\mathrm{a}}$ \\
& $\mathrm{F} 3$ & $3,41^{\mathrm{a}}$ & $3,36^{\mathrm{a}}$ & $3,59^{\mathrm{a}}$ \\
& $\mathrm{F} 4$ & $3,33^{\mathrm{a}}$ & $3,40^{\mathrm{a}}$ & $3,70^{\mathrm{a}}$ \\
Maduro $^{* * *}$ & $\mathrm{~F} 1$ & $3,80^{\mathrm{a}}$ & $3,89^{\mathrm{a}}$ & $3,80^{\mathrm{a}}$ \\
& $\mathrm{F} 2$ & $3,83^{\mathrm{a}}$ & $3,91^{\mathrm{a}}$ & $3,89^{\mathrm{a}}$ \\
& $\mathrm{F} 3$ & $3,54^{\mathrm{a}}$ & $3,68^{\mathrm{a}}$ & $3,60^{\mathrm{a}}$ \\
& $\mathrm{F} 4$ & $3,45^{\mathrm{a}}$ & $3,54^{\mathrm{a}}$ & $3,51^{\mathrm{a}}$ \\
\hline
\end{tabular}

${ }^{\star}$ Letras iguais na mesma coluna não diferem estatisticamente a $5 \%$ de probabilidade; ${ }^{* \star} \mathrm{F} 1$ ( $0,3 \%$ de goma xantana); F2 ( $0,3 \%$ de goma xantana e $5 \%$ de xarope de glicose); F3 ( $0,5 \%$ de amido modificado); F4 (0,5\% de amido modificado e 5\% de xarope de glicose); ${ }^{* * *} \mathrm{~F} 1$ (sem aditivos); F2 (0,5\% de pectina); F3 (0,3\% de goma xantana); F4 (0,5\% de amido modificado e $5 \%$ de xarope de glicose).

Tabela 2. Efeito do armazenamento sobre a acidez total titulável de doces de umbu verde e maduro.

\begin{tabular}{ccccc}
\hline \multirow{2}{*}{ Doce } & Formulação & \multicolumn{3}{c}{ Tempo de armazenamento (dias) } \\
\cline { 3 - 5 } & & 0 & 60 & 120 \\
\hline Verde $^{* *}$ & F1 & $0,39^{\mathrm{a}}$ & $0,49^{\mathrm{a}}$ & $0,46^{\mathrm{a}}$ \\
& $\mathrm{F} 2$ & $0,44^{\mathrm{a}}$ & $0,50^{\mathrm{a}}$ & $0,48^{\mathrm{a}}$ \\
& $\mathrm{F} 3$ & $0,56^{\mathrm{a}}$ & $0,56^{\mathrm{a}}$ & $0,54^{\mathrm{a}}$ \\
& $\mathrm{F} 4$ & $0,66^{\mathrm{a}}$ & $0,70^{\mathrm{a}}$ & $0,59^{\mathrm{a}}$ \\
Maduro $^{* * *}$ & $\mathrm{~F} 1$ & $0,32^{\mathrm{a}}$ & $0,40^{\mathrm{a}}$ & $0,39^{\mathrm{a}}$ \\
& $\mathrm{F} 2$ & $0,33^{\mathrm{a}}$ & $0,43^{\mathrm{a}}$ & $0,40^{\mathrm{a}}$ \\
& F3 & $0,35^{\mathrm{a}}$ & $0,48^{\mathrm{a}}$ & $0,44^{\mathrm{a}}$ \\
& F4 & $0,43^{\mathrm{a}}$ & $0,60^{\mathrm{a}}$ & $0,50^{\mathrm{a}}$ \\
\hline
\end{tabular}

${ }^{*}$ Letras iguais na mesma coluna não diferem estatisticamente a $5 \%$ de probabilidade; ${ }^{* *} \mathrm{~F} 1$ ( $0,3 \%$ de goma xantana); F2 ( $0,3 \%$ de goma xantana e $5 \%$ de xarope de glicose); F3 (0,5\% de amido modificado); F4 (0,5\% de amido modificado e $5 \%$ de xarope de glicose); ${ }^{* * *} \mathrm{~F} 1$ (sem aditivos); F2 (0,5\% de pectina); F3 (0,3\% de goma xantana); F4 (0,5\% de amido modificado e $5 \%$ de xarope de glicose). 
formulação F3 do doce de umbu verde, na qual este parâmetro se manteve estável. Posteriormente se verificou uma tendência à estabilidade na acidez titulável das formulações F1, F2 e F3, de ambos os doces, até o final do armazenamento.

Resultados semelhantes foram encontrados por Xavier (1999), em análise da vida de prateleira de doce em massa de umbu (polpas mistas), e por Policarpo et al. (2007), em estudo da conservação de doce de umbu verde armazenado em embalagens de polipropileno à temperatura ambiente $\left(33^{\circ} \mathrm{C}\right)$ durante 90 dias.

As Figuras 1 e 2 demonstram tendência significativa $(\mathrm{p}<0,05)$ a um aumento dos sólidos solúveis totais, em todas as formulações de doce de umbu verde e maduro durante o armazenamento, aplicando-se regressão linear.

As formulações F1 e F2 do doce de umbu verde foram as que apresentaram um teor de sólidos solúveis mais baixo no início e ao final do armazenamento. Já para o doce de umbu maduro, as formulações F3 e F4 apresentaram os maiores teores de sólidos solúveis totais $\left(78^{\circ} \mathrm{Brix}\right)$ ao final do armazenamento. O aumento dos sólidos solúveis ocorreu, provavelmente, devido à evaporação de água durante a estocagem a uma temperatura relativamente alta $\left(30{ }^{\circ} \mathrm{C}\right)$ e um teor de umidade de $75 \%$, em relação à atividade de água deste alimento $(0,74-0,82)$. É possível que a permeabilidade do material de embalagem (BUREAU; MULTON, 1995), permita a migração da água para o ambiente.

Comportamentos semelhantes foram observados por Rocha e Magalhães (2000) no acompanhamento de vida de prateleira de doce de manga espada, cujo teor de sólidos solúveis variou de 62 a $65^{\circ}$ Brix ao final de 180 dias de armazenamento.

Policarpo et al. (2007), estudando conservação de doce de umbu verde armazenado em embalagem de polipropileno na temperatura de $33{ }^{\circ} \mathrm{C}$ durante 90 dias, observou aumento de sólidos solúveis em todas as formulações estudadas, assim como Nascimento et al. (2003), em trabalho similar com doce em massa de casca de maracujá.

As Figuras 3 e 4 mostram uma redução linear na atividade de água ao longo do tempo de armazenamento em ambos os doces. Ao final do armazenamento, a formulação F3 do doce de umbu maduro apresentou maior redução no teor de água e a formulação F2, menor. Esta redução se deve à hidrolise de açúcares não redutores a redutores, os quais são mais higroscópicos e depressores de atividade de água. Tendências
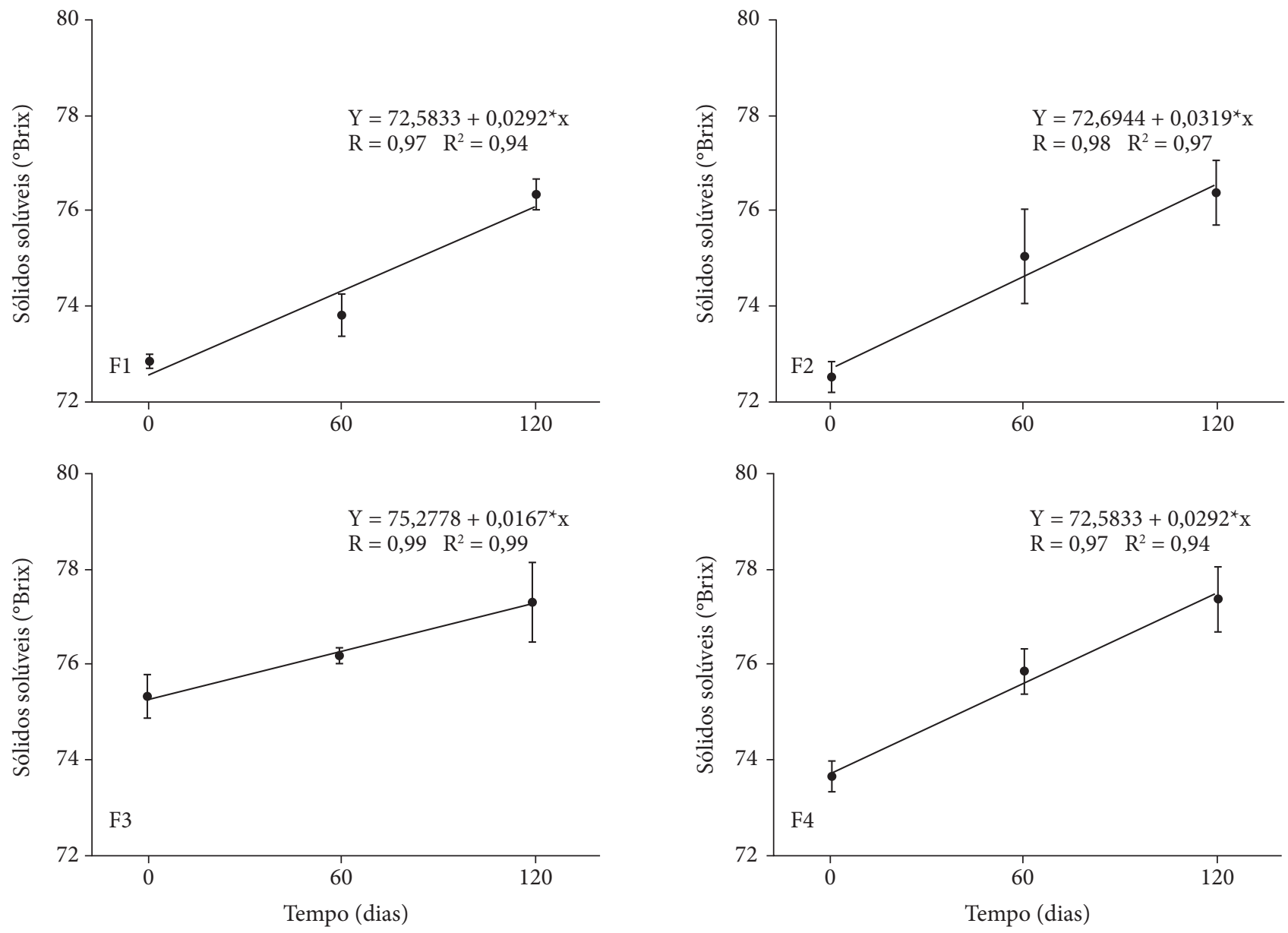

Figura 1. Efeito do armazenamento sobre os sólidos solúveis totais ( ${ }^{\circ}$ Brix) de doces de umbu verde. F1 (0,3\% de goma xantana); F2 (0,3\% de goma xantana e 5\% de xarope de glicose); F3 (0,5\% de amido modificado); F4 (0,5\% de amido modificado e 5\% de xarope de glicose). 

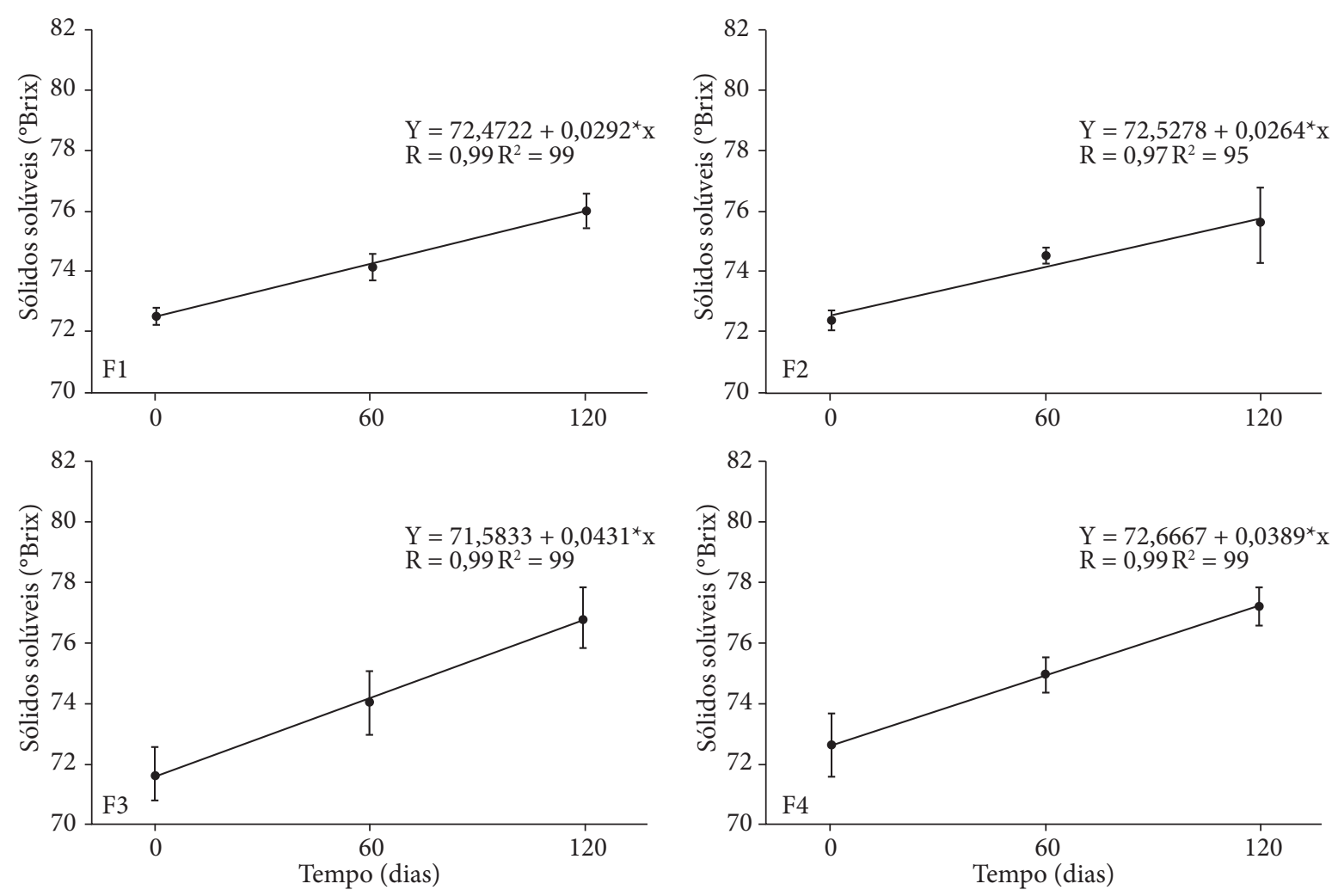

Figura 2. Efeito do armazenamento sobre sólidos solúveis totais ( ${ }^{\circ}$ Brix) de doces de umbu maduro. F1 (sem aditivos); F2 (0,5\% de pectina); F3 ( $0,3 \%$ de goma xantana); F4 (0,5\% de amido modificado e 5\% de xarope de glicose).
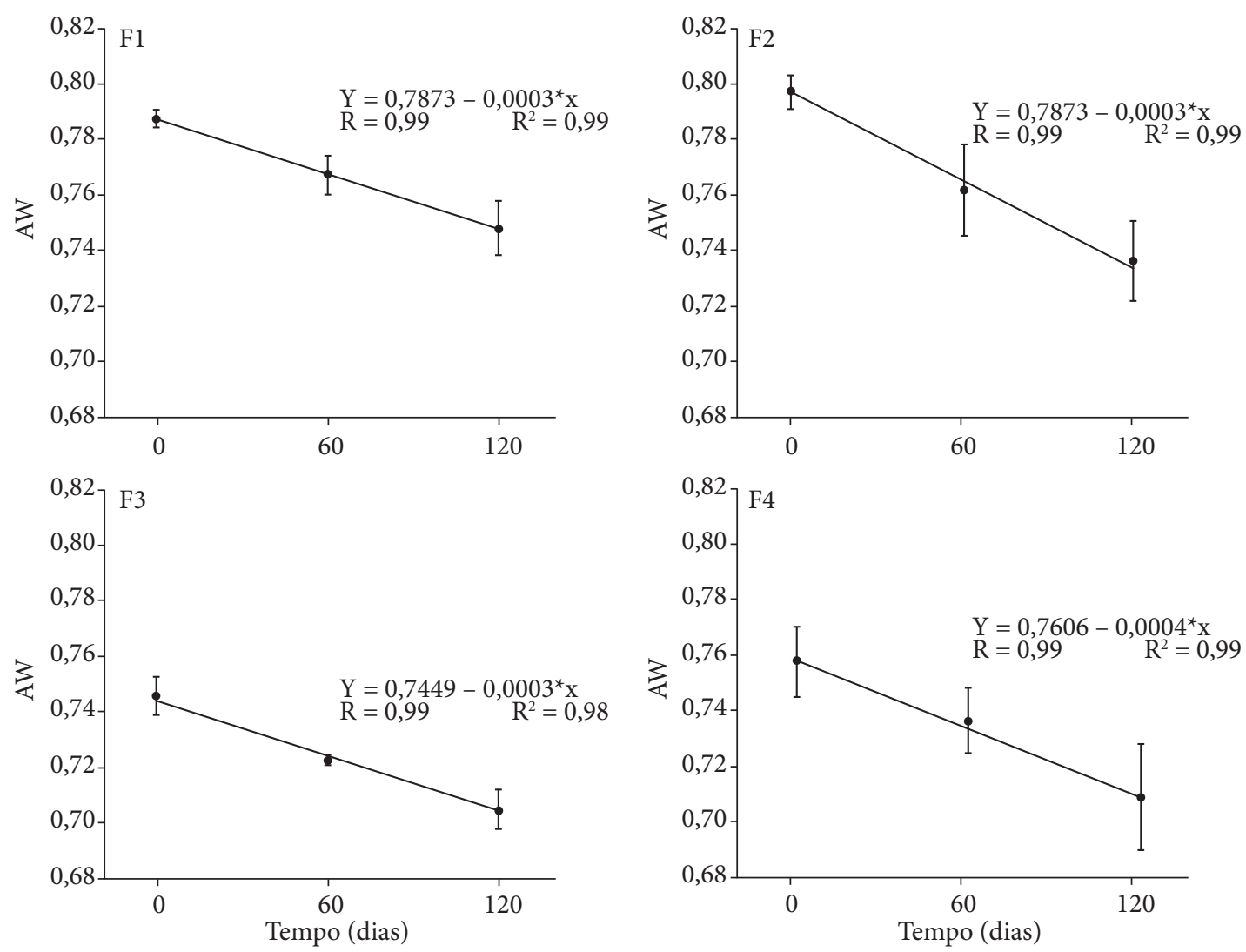

Figura 3. Efeito do armazenamento sobre a aw de doces de umbu verde. F1 (0,3\% de goma xantana); F2 (0,3\% de goma xantana e 5\% de xarope de glicose); F3 (0,5\% de amido modificado); F4 (0,5\% de amido modificado e 5\% de xarope de glicose). 

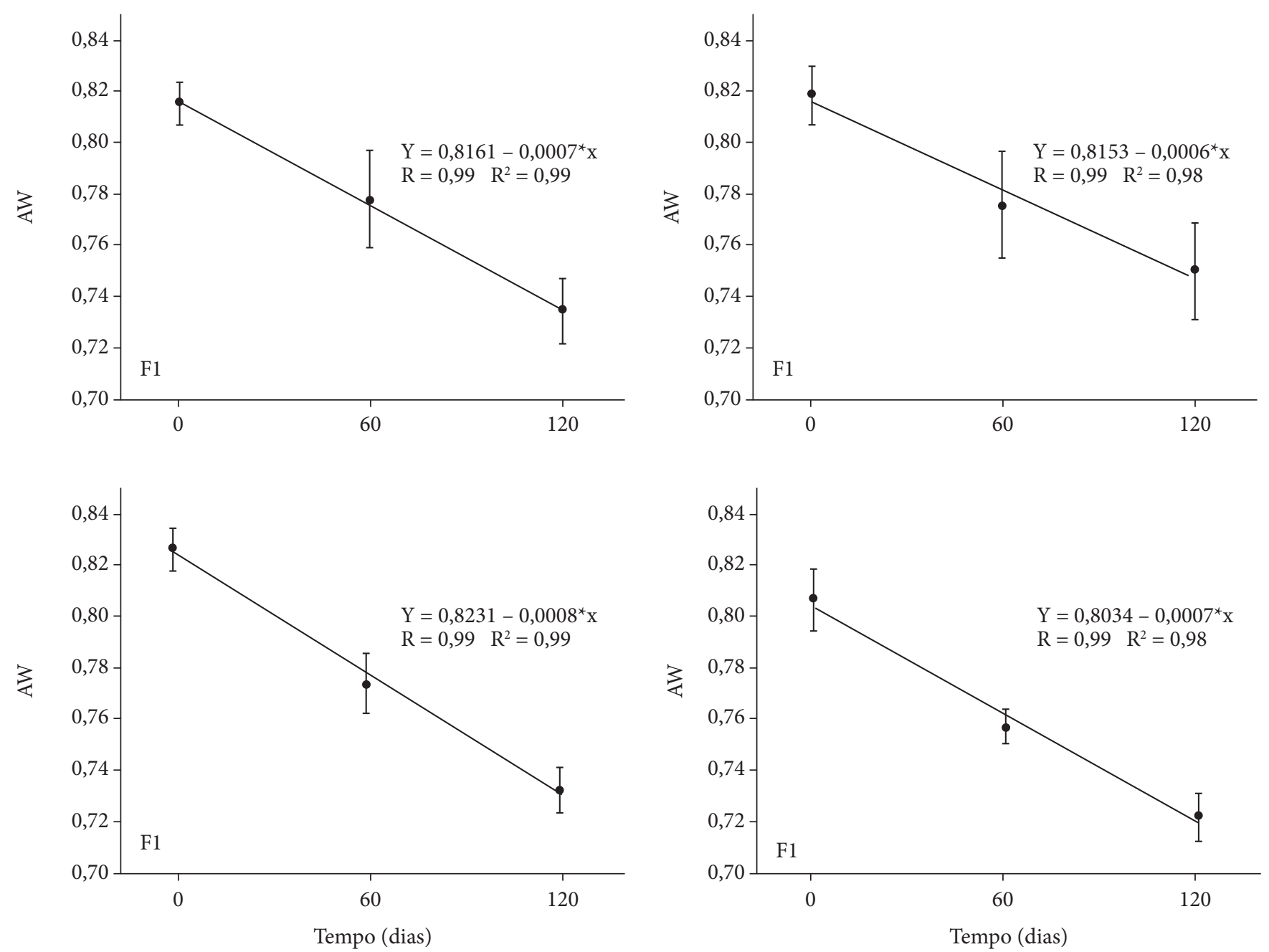

Figura 4. Efeito do armazenamento sobre aw de doces de umbu maduro. F1 (sem aditivos); F2 (0,5\% de pectina); F3 (0,3\% de goma xantana); F4 (0,5\% de amido modificado e $5 \%$ de xarope de glicose).

similares foram encontradas no estudo do armazenamento de doce em massa de casca de maracujá e de doce de umbu verde durante 90 dias por Nascimento et al. (2003) e Policarpo et al. (2007), respectivamente. Jorge et al. (2007), ao estudar preservação de polpa de umbu verde e madura por métodos combinados, verificaram que as amostras contendo sacarose diminuíram significativamente a atividade de água durante o armazenamento.

Ao longo do armazenamento verificou-se, através das Figuras 5 e 6, um aumento dos açúcares redutores em decorrência da hidrólise dos açúcares não redutores, promovido pela acidez e estocagem à temperatura acima da temperatura ambiente (BOBBIO, P. A.; BOBBIO, F. O., 1995), o qual se observa mais acentuadamente no doce de umbu maduro, para as formulações F1 e F4. Na formulação F4, a incorporação de amido, macromolécula de unidades de glicose, parece contribuir adicionalmente para o aumento de açúcares redutores, uma vez que esta substância também é passível de ser hidrolisada em glicose a partir dos 60 dias. A formulação F2 tendeu a estabilizarse após 60 dias de armazenamento.
A adição de goma xantana, xarope de glicose e amido contribuiu para aumentar as concentrações de açúcares redutores do doce de umbu verde.

O processo da inversão teve início durante a cocção, quando, devido à acidez e à alta temperatura, a sacarose transforma-se em glicose e frutose (JACKIX, 1988). Cardoso (1994), estudando geleias de jambo com casca e sem casca, observou que tanto a $25^{\circ} \mathrm{C}$ como a $35^{\circ} \mathrm{C}$ o teor de açúcares redutores aumentou à medida que se prolongava o tempo de armazenamento, em virtude da hidrólise ácida da sacarose. Policarpo et al. (2007), em estudo com produto similar no estádio de maturação verde, armazenado à temperatura de $33^{\circ} \mathrm{C}$ em embalagem de polipropileno, encontraram resultados semelhantes após 45 dias.

Em concordância com o aumento de açúcares redutores, observa-se nas Figuras 7 e 8 a redução de açúcares não redutores pelas razões já discutidas anteriormente a partir de 60 dias de armazenamento em ambos os doces. Na formulação F4 do doce de umbu verde, verificou-se redução acentuada até 60 dias, após 

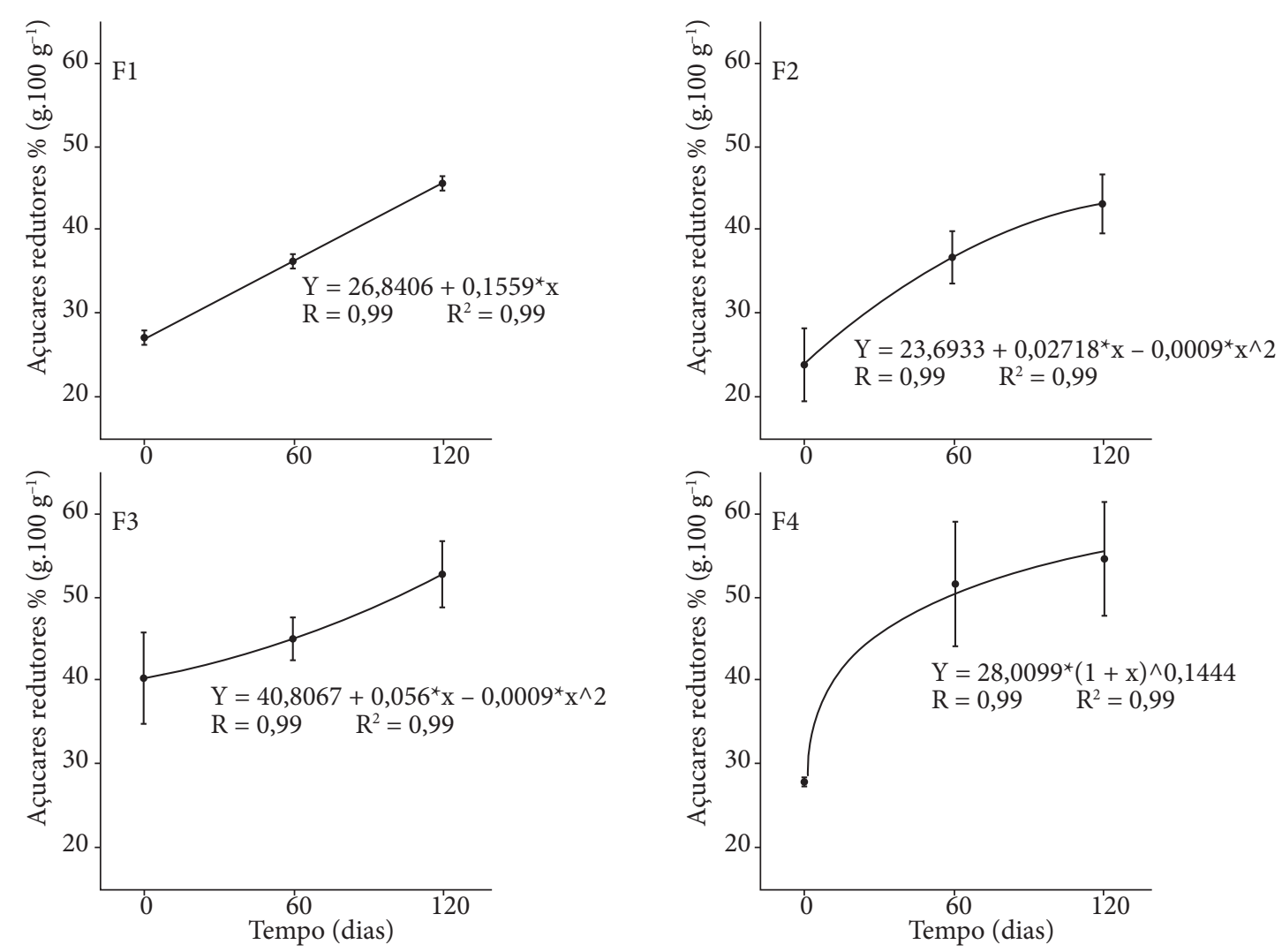

Figura 5. Efeito do armazenamento sobre açúcares redutores de doces de umbu verde. F1 (0,3\% de goma xantana); F2 (0,3\% de goma xantana e 5\% de xarope de glicose); F3 (0,5\% de amido modificado); F4 (0,5\% de amido modificado e 5\% de xarope de glicose).
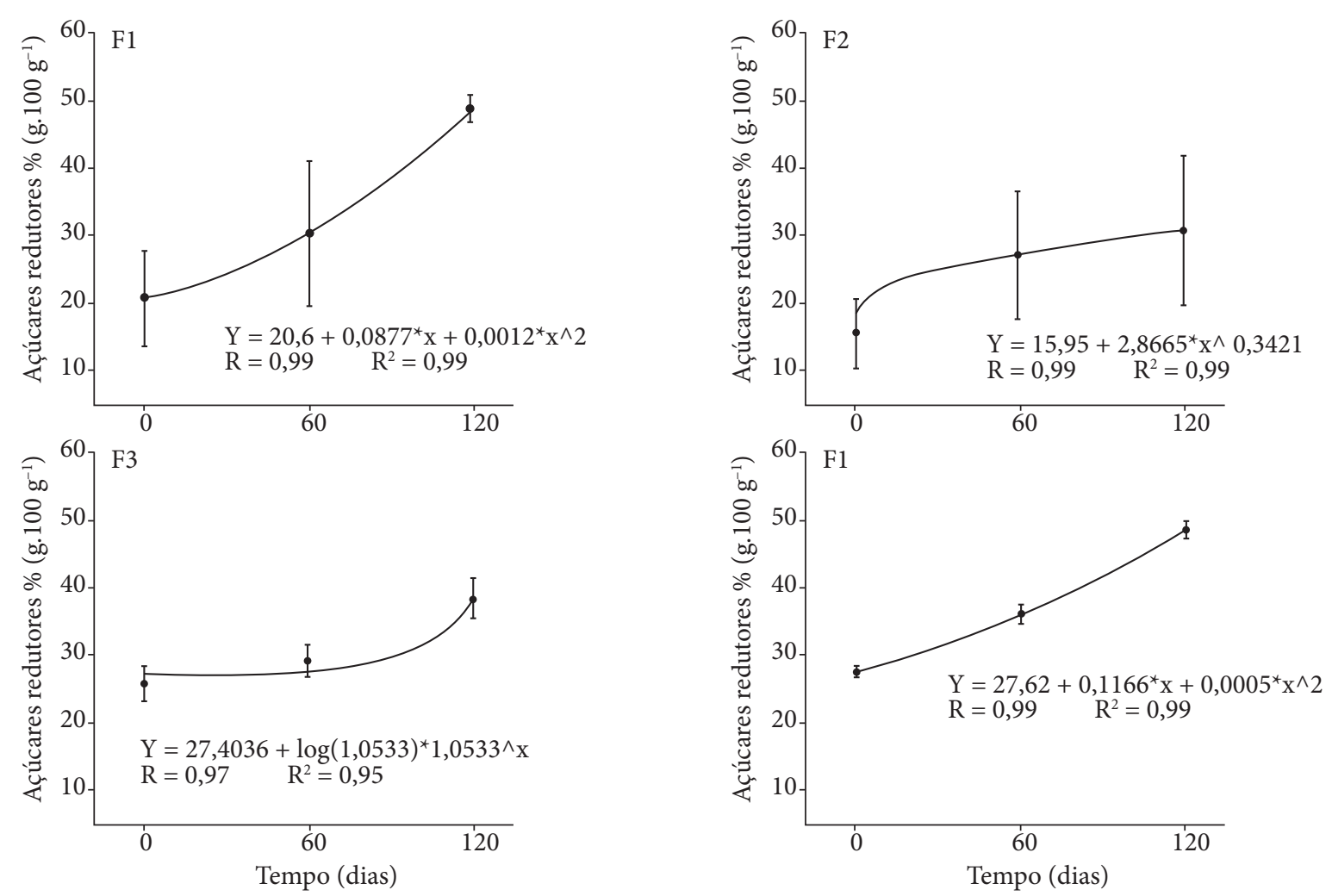

Figura 6. Efeito do armazenamento sobre açúcares redutores de doces de umbu maduro. F1 (apenas, correção de pH); F2 (0,5\% de pectina); F3 (0,3\% de goma xantana); F4 (0,5\% de amido modificado e 5\% de xarope de glicose). 

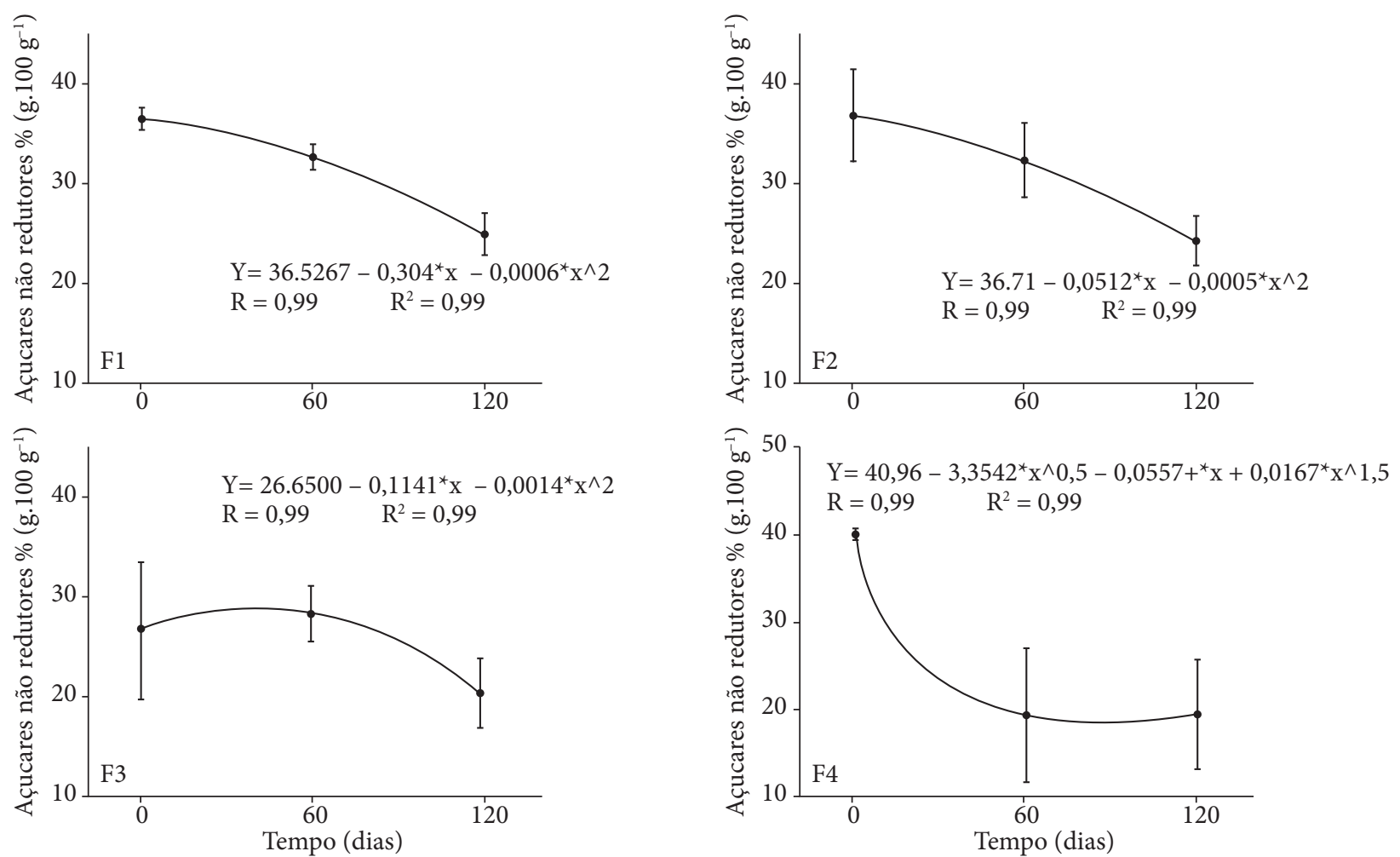

Figura 7. Efeito do armazenamento sobre açúcares não redutores de doces de umbu verde. F1 (0,3\% de goma xantana); F2 (0,3\% de goma xantana e 5\% de xarope de glicose); F3 (0,5\% de amido modificado); F4 (0,5\% de amido modificado e 5\% de xarope de glicose).
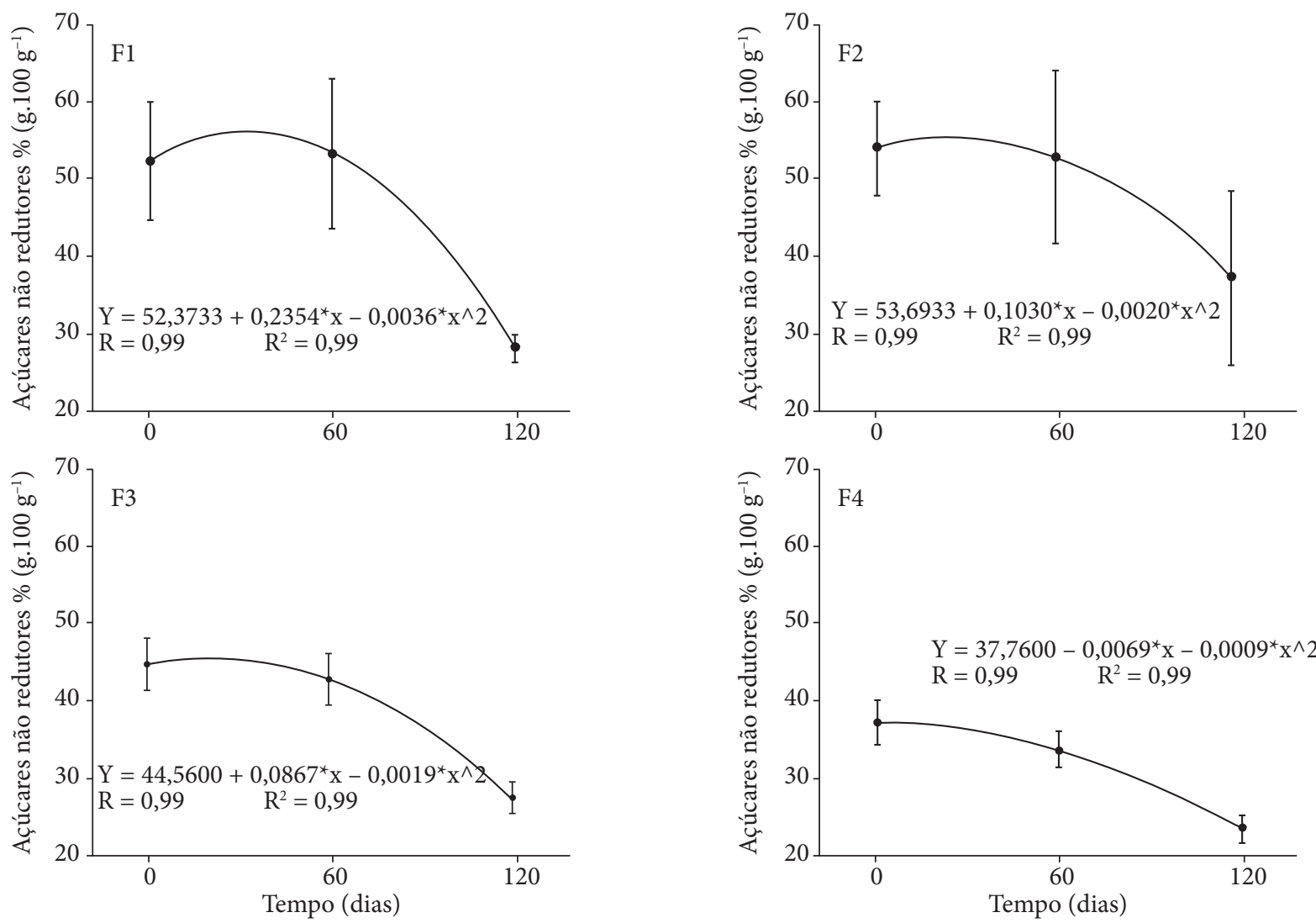

Figura 8. Efeito do armazenamento sobre açúcares não redutores de doces de umbu maduro. F1 (sem aditivos); F2 (0,5\% de pectina); F3 (0,3\% de goma xantana); F4 (0,5\% de amido modificado e 5\% de xarope de glicose). 
os quais tendeu a estabilizar-se. Resultados semelhantes foram reportados por Policarpo et al. (2007), estudando conservação de doce de umbu verde à temperatura de $33^{\circ} \mathrm{C}$, que também apresentaram hidrólise acentuada em todas as formulações avaliadas durante 90 dias de armazenamento. Nachtigall et al. (2004), no estudo sobre o armazenamento de geleias de amorapreta de baixa caloria, encontraram concomitante decréscimo da sacarose e acréscimo dos açúcares redutores, confirmando resultados obtidos neste trabalho.

\subsection{Análises microbiológicas}

Os doces de umbu verde e maduro apresentaram-se negativos quanto à presença de bolores e leveduras em todas as formulações $\left(<10\right.$ UFC.g $\left.{ }^{-1}\right)$, mostrando que foram obtidos dentro dos padrões de higiene, garantindo ao produto no final de 120 dias padrões de qualidade de acordo com a recomendação da Agência Nacional de Vigilância Sanitária (BRASIL, 2001). Resultados similares foram também observados por Policarpo et al. (2007), Nachitigall (2004) e Falcó et al. (1993) no estudo da conservação de doces de umbu verde, geleias de amora-preta e doce cremoso de morango, respectivamente, durante 90 dias de armazenamento.

\section{Conclusões}

Aos 120 dias de armazenamento os produtos foram microbiologicamente estáveis. A formulação $\mathrm{F} 2$ (com 0,5\% de pectina) para doce de umbu maduro e F2 (com $0,3 \%$ de goma xantana e $0,5 \%$ de xarope de glicose) para doce de umbu verde foram as que menos sofreram alterações nas características físico-químicas, assim como apresentaram menor hidrólise de açúcares não redutores e, portanto, recomenda-se o uso destas formulações para o processamento e consequente agregação de valor a este produto.

\section{Referências bibliográficas}

ASSOCIATION OF OFFICIAL ANALITICAL CHEMISTRY - AOAC. Official methods of analysis of the association of analitical chemistry. $11 \mathrm{ed}$. Washington, 1992.

BOBBIO, P. A.; BOBBIO, F. O. Química do processamento de alimentos. 2 ed. São Paulo: Varela, 1995.

BRASIL. Resolução RDC n. 12, de 2 de janeiro de 2001. Regulamento técnico sobre padrões microbiológicos para alimentos. Diário Oficial da União, Poder Executivo, Brasília, DF, 10 jan. 2001. Disponível em: <www.anvisa.com.br>. Acesso em: 01 dez. 2007.

BUREAU, G.; MULTON, J. L. Embalage de los alimentos de gran consumo. Zaragoza: Editorial Acríbia S.A., 1995. 748 p.

CARDOSO, L. R. Estabilidade de geléia de jambo vermelho (Eugenia malaccensis, Lin.) em copo de vidro. Campinas, 1994. 181 p. Tese (Doutorado em Tecnologia de Alimentos) - Universidade Estadual de Campinas - UNICAMP.

FALCÓ, A. S. et al. Empleo de métodos combinados para la conservacion de una mermelada concentrada obtenida a partir de resíduos de fresas. Revista Alimentaria, n. 242, p. 69-71, 1993.

FONSECA, J. S.; MARTINS, G. A.; TOLEDO, G. L. Estatística aplicada. 2 ed. São Paulo: Atlas S.A., 1995. p. 78-109.

INSTITUTO ADOLFO LUTZ - IAL. Normas Analíticas do Instituto Adolfo Lutz. São Paulo, 1985.
JACKIX, M. H. Doces, geléias e frutas em calda. São Paulo: Ícone, 1988.

JORGE, É. C. et al. Preservation of umbu (Spondias tuberosa Arr. Cam.) pulp in the green stage of maturation by combined methods. Journal of Food Processing and Preservation, v. 31, n. 3, p. 286-297, 2007.

KHOURYEH, H. A.; ARAMOUNI, F. M.; HERALD, T. J. Physical, chemical and sensory properties of sugar-free jelly. Journal of Food Quality, v. 28, n. 2, p. 179-190, 2005.

MAO, R.; TANG, J.; SWANSON, B. G. Water holding capacity and microstructure of gellan gels. Carbohydrate Polymers, v. 46, p. 365-371, 2001.

MARTINS, M. L. A. et al. Características do doce em massa de umbu verde e maduro e aceitação pelos consumidores. Pesquisa Agropecuária Brasileira, v. 42, n. 9, p. 1329-1333, 2007.

MOURA, S. C. S. R. et al. Determinação da vida-de-prateleira de maçãpassa por testes acelerados. Ciência e Tecnologia de Alimentos, v. 27, n. 1, p. 141-148, 2007.

NACHTIGALL, A. M. et al. Geléias light de amora-preta. Boletim do Centro de Processamento de Produtos Agropecuários, v. 22, n. 2, p. 337-353, 2004.

NASCIMENTO, R. M. F.; BORGES, S. V.; OLIVEIRA, L. F. Alterações microbiológicas e físico-químicas de doces em massa da casca do maracujá em condições aceleradas de armazenamento. In: SIMPÓSIO DE CIÊNCIA DOS ALIMENTOS, 2., 2003, Florianópolis. Anais... (CD-ROM)

PINTO, P. R. et al. Efeito do processamento de doce em massa de umbu verde e maduro sobre sua composição e aceitação. Alimentos e Nutrição, v. 12, n. 1, p. 45-53, 2001.

POLICARPO, V. M. N. et al. Aprovechamiento de la pulpa de umbu (Spondias tuberosa, Arr. Cam.) verde como alternativa para la producción de dulces em masa. Alimentaria, n. 344, p. 75-78, 2002.

POLICARPO, V. M. N. et al. Green umbu (Spondias Tuberosa Arr. Cam.) preserve: physical, chemical and microbiological changes during storage. Journal of Food Processing and Preservation, v. 31, n. 2, p. 201-210, 2007.

RENARD, D.; Van de VELDE, F.; VISSCHERS, R. W. The gap between food gel structure, texture and perception. Food Hidrocolloids, v. 20, n. 4, p. 423-431, 2006.

ROCHA, E. M.; MAGAlHÃES, M. M. A. Estudo de vida de prateleira do doce em massa de manga espada. In: CONGRESSO BRASILEIRO DE CIÊNCIA E TECNOLOGIA DE ALIMENTOS, 17., 2000, Fortaleza. Resumos... Fortaleza: UFC, 2000.

SPEACK, M. L. Compendium of methods for the microbiological examinations of foods. Washington: American Public Heath Association, 1976.

VASQUES, A. R. et al. Avaliação sensorial e determinação de vidade-prateleira de maçãs desidratadas. Ciência e Tecnologia de Alimentos, v. 26, n. 4, p. 759-765, 2006.

WICKLUND, T. et al. Antioxidant capacity and colour of strawberry jam as influenced by cultivar and storage conditions. Lebensmittel Wissensenschaft und Technologie, v. 38, n. 4, p. 387-391, 2005.

XAVIER, A. N. Caracterização química e vida de prateleira do doce em massa de umbu (Spondias tuberosa Arruda Câmara). Belo Horizonte, 1999. 82 p. Dissertação (Mestrado em Ciência dos Alimentos) - Universidade Federal de Minas Gerais - UFMG. 